\title{
Social Harmony in Decision Making: Costs and Benefits in Chinese Society
}

\author{
Robert J. Taormina \\ Psychology Department, University of Macau, Macau (SAR), China \\ Email: taormina@umac.mo
}

Received March 2014

\begin{abstract}
Social harmony in Chinese society was examined in relation to decision making. From a historical perspective, it was noted that social harmony evolved as a consequence of the prescriptions Confucius developed in response to thousands of years of war in Chinese history. Social harmony was found to have not only benefits, but also some costs in regard to decision making, especially group decision making, in the hierarchically structured Chinese society. The costs were examined in relation to the problems of groupthink that affect group decisions when there is a strong power hierarchy in society. Groupthink was analyzed for factors that cause it, and those factors were found to be characteristic of Chinese society. Confucian principles of virtuous behavior, namely, courage, humanity, justice, temperance, and wisdom, were examined to assess whether they could prevent groupthink, and were found to provide the means by which Chinese leaders could avoid problems in group decision making. It was thus proposed that leaders could benefit by developing such virtues in their personal lives, which would facilitate harmony in decision making.
\end{abstract}

\section{Keywords}

Social Harmony, China, Decision Making, Groupthink, Confucius, Leadership

\section{Introduction}

Any time that a decision is made, which affects people other than the decision maker, there always is a chance that those other people will be unhappy with that decision, and this has the potential to create social disharmony. In western societies, where there exists a strong individualism that makes each side want an outcome that is favorable to them, decision making is expected to create disputes because of positive outcomes for one side and negative outcomes for the other side. Thus, western societies use law courts to resolve disputes.

In China, however, for the last 2000 years since the social philosophy of Confucius was instituted in the society, social harmony has been the guiding principle in human interaction, such that a hierarchical social order requires placing one's personal desires at a lower priority if they conflict with what the social group desires. One benefit of having social harmony as a guiding value in Chinese culture is that it has led to less reliance on the open conflict that occurs when law courts are used to resolve conflicts.

There are also, however, some negative consequences to having social harmony as a cultural value, and those negative consequences should be examined in order to find ways to reduce them. Therefore, this article ex- 
amines: 1) The historical roots of social harmony in Chinese society, 2) the benefits that institutionalized social harmony has had, 3) costs (or problems) associated with it, 4) suggested ways to avoid those problems, and 5) whether Chinese leaders have the ability to deal with those problems.

\section{Historical Roots of Social Harmony}

The historical roots of social harmony in China are based firmly in the period of conflict that occurred prior to the Warring States Period (476-221 BC). It may seem ironic that social harmony is rooted in the numerous wars that troubled China for hundreds of years. It is known that Confucius (551-479 BC) lived during a time of military and political turmoil [1], when China was composed of many small warring states.

As further evidence of the preeminence of war during his time, Confucius was a contemporary of Sun Tzu (544-496 BC), the renowned general who wrote The Art of War [2], which is a famous book on military strategy.

Confucius was born and lived (near Qufu) in the state of Lu, adjacent to the state of Wu (Shandong Province), under the Zhou Dynasty. Major battles were fought there during Confucius' lifetime, one of which lasted 14 years (519-506 BC) between the Wu and Chu, when King Lu of Wu (513-494 BC) asked Sun Tzu to lead his forces against Chu.

These wars during Confucius' life led to the fall of the Zhou Dynasty (consisting of the states of Qin in the Northwest, Chu between the Yellow and Yangtze rivers, and $\mathrm{Wu}$, along the coast), and later led to the 255-year-long “Warring States Period” (476-221 BC). Even during Confucius’ time, the wars were so many, so frequent, and so devastating to the Chinese people that the extensive death and destruction may be considered to have influenced Confucius to develop his philosophy of social harmony [3].

\subsection{Wars, Warlords, and Decision Making}

During the thousands of years prior to the unification of China (221 BC), countless warlords ruled their own territories. As they obtained power at the point of the sword, they were indeed all-powerful; and as they were generals, they had the absolute power of life and death over everyone who lived under them. The warlords had murdered populations of entire villages and could execute anyone at will and without providing any excuse. They could execute their own servants for any reason, even for using the wrong word when speaking. Thus, anyone who could not control what they did and what they said could be executed. This was a Darwinian process, namely, people who were able to control their own behavior and words learned to adapt to living under the all-powerful warlords, and were more likely to survive.

\subsection{Obedience, Subservience, and Survival}

Under the Chinese warlords, being obedient and subservient to those in power became the way of life. If a person was outspoken, for example, in complaining about what the warlord was doing, that person could be tortured and/or executed. Even if one was not openly complaining, but spoke only to a few other people, it was possible that one might be overheard by someone loyal to the ruler, or that one of the people one spoke to might tell the ruler what that person had said, which could also result in torture and/or death. Disobeying the ruler could also result in the same fate. Also, as the tortures and executions were often carried out in public, this strengthened the idea that it is better for a person to always remain quiet, obedient, and subservient. And, over the thousands of years that the warlords ruled in this way, subservient behavior became a part of Chinese culture. It should be noted that subservient behavior was not introduced by Confucius because it had existed for many eons before Confucius was even born. Furthermore, during the Warring States Period, which lasted for 255 years after his death, the same tyrannical behaviors continued to be practiced, that is, until the rule of Emperor Han Wudi (汉武帝, 156-87 BC), who adopted Confucian ideas [4].

\section{Benefits of Traditional Social Harmony}

Confucius' ideas about life were not widely accepted while he was alive. In fact, the warlords were actually concerned that the type of laws and ruler ship that they practiced might be seen as flawed by people who listened to Confucius. Therefore, initially, the various rulers rejected Confucius, and, in 497 BC, one ruler exiled Confucius [5], and others were so offended by his political views that they ordered the execution of his follow- 
ers and the burning of books containing Confucian ideas [6]. It was only the emperors of the Han Dynasty who realized that his ideas about social harmony could have benefits for the emperor as well as for society.

\subsection{Stable Social Hierarchy}

Confucius' ideas were designed to produce harmony throughout society, from the basic family relationships all the way up to the governance of the state. The founding principles of Confucius' ideal society are epitomized in the Five Cardinal Relationships, called the “wu-lun" (五伦关系) [7]. These are: 1) The emperor over the subject; 2) father over the son; 3) husband over the wife; 4) elder brother over the younger one; and 5) Friend and friend. (Many western thinkers assume that the friend-friend relationship is equal, but, in practice, it is implicitly understood that the elder friend is afforded higher status.) Thus, in each relationship, there is a hierarchical (superior to subordinate) order, such that the person in the superior position possesses power and authority to rule (give orders) and be served. Every person was expected to be obedient and show respect to the person in the superior position (e.g., the subject serves the emperor, the wife serves the husband); and, reciprocally, the person in the superior position had the responsibility to love and protect the person(s) in the subordinate position. When everyone knew his or her place in the hierarchically structured society, everyone would benefit in mutually beneficial, reciprocal relationships.

\subsection{Social Harmony}

One thing is certain, i.e., that having everyone living in social harmony is a true benefit for the society. When an entire society lives in harmony, it means that both the state and the people benefit. The state benefits because there is minimal internal strife (such as civil unrest and rioting), which is economically costly, as is often found in societies where conflict is openly expressed. But in a socially harmonic society, life is more peaceful and orderly. The people also benefit because they are not disturbed by open aggression and thus live a life that is more pleasant. Beyond just having a peaceful society, the individual can benefit in personal ways as well. That is, as Maslow [8] explained, all individuals have five levels of needs that, when satisfied, enable them to achieve a good life.

Maslow described how the satisfaction of basic needs allows one to pursue higher-order needs. There are five levels of needs. The first is the need for basic things, such as food and water that are required to survive physiologically. A society that lives in peace will be more likely to have a productive economy because there is no destruction to the agriculture (which could happen in countries that have riots and civil wars). The next level is the satisfaction of the need for safety and security. And, of course, when people live in social harmony, they do not need to fear physical aggression by angry groups. When those needs are satisfied, one can feel free to seek and find the closeness that all human beings need from family, friends, and a lover or a spouse. Achieving this allows one the opportunity to find esteem in the eyes of others. And when that is achieved, one will have the chance to live out one's inner-most desires, i.e., to be the person one always wanted to be.

\section{The Costs of a Strict Social Hierarchy}

Although a strict social hierarchy provides benefits to both interpersonal relationships and to society overall, there are also aspects of such an "institutionalized social hierarchy" that can, and often do, have unwanted side effects and outcomes. These are manifested in feelings of "hopelessness" for people at the lower end of the hierarchy, and, more critically, in terms of fiascos in decision making. The feelings of the subordinates are addressed first, followed by the major concern of this paper, namely, the difficulties that the structural social hierarchy engenders in the form of problematic decisions that are made by groups.

\subsection{Hopelessness among Subordinates}

The strict, power-dominated social hierarchy that evolved in China for thousands of years before Confucius, and the institutionalized social hierarchy that became so strong for the two thousand years since its adoption by the Han Dynasty makes this is a deeply rooted characteristic of Chinese society. Thus, in China, the way decisions are made is an overwhelmingly "top-down" process, i.e., where the person at the top of the social hierarchy makes the decisions, including those that affect the lives of his subordinates, for better or worse. Thus, there are two powerful factors that make it difficult for subordinates to voice their opinions. And these are: 1) the long 
history that has made submissive subservience necessary for those at the bottom to survive, and 2) the "right" of the person in power (at the top) to rule however he sees fit, including the right to appoint friends, associates, and relatives to posts of authority to administer the leader's directives, a process that is known as "nepotism."

These factors lead the subordinates to conclude that they must do as they are told without objection, which could create a feeling of depression when they believe that the orders are not good or appropriate. Also, a feeling of powerlessness develops when the subordinates think there is no chance for them to change either the orders or those who give the orders. Together, these factors lead to a feeling of hopelessness about their condition. As a caveat to this description, it may be noted that Confucius addressed this concern by pointing out that a person (at any level) should be diligent, be virtuous in their own tasks, and should study to improve themselves. That is, Confucius laid the foundation for leaders to find helpers from among subordinates who excel in their knowledge and in their work (even if such people are rarely found).

\subsection{Groupthink: Basis for Poor Decisions}

Leaders who have tremendous power tend to rely only on themselves, or on a few favorite individuals, such as relatives, whose advice they might deign to consider. But when the advisors are hand-chosen relatives or friends, they are unlikely to have developed expert leadership abilities. And, of course, the leader also is unlikely to have developed leadership skills if the leader grew up in a family that had power, i.e., being wealthy they have no pressure to better themselves. Therefore, whether the leader decides alone, or decides with advice from a select few advisors, there could very well be poor decisions.

Groupthink is a term that was introduced by Irving Janis [9] in a book about fiascos (terrible disasters) in decision making that were made by powerful leaders in history partly because they held great power, which made them unreachable, and partly because their advisors failed to provide good counsel as a consequence of their social status that came with being chosen as elite advisors.

An example of such decision-making disasters was the decision by the powerful General Hideki To jo, who had been the Prime Minister of Japan (whom no one dared to oppose), to attack Pearl Harbor on 7 December 1941; although the attack had a mild short-run success, in the long term the war with the more powerful enemy ended in a tremendous defeat for Japan. Another example is Adolf Hitler's decision to invade Russia: In May 1940, Hitler, another supremely powerful leader whom no one would oppose, began a war on the western front with France, and only one year later, in June 1941, Hitler decided to invade Russia, resulting in wars on both the eastern and western borders that weakened his army by splitting the German forces to move in opposite directions.

Although Groupthink is a complicated social process, the central elements are described here to summarize how it works and why it leads to faulty decisions. Groupthink has three "precursors," i.e., 1) The group has a powerful, directive leader who promotes his/her own preferred solution, and this is characteristic of Chinese leaders (as explained in the foregoing historical description); 2) the group is a "highly cohesive" unit, which means the members are known to each other and stay together, as revealed in the tendency for Chinese leaders to choose family members and friends; and 3) the group is isolated from judgments of other qualified people, which is because the people at the top of the hierarchy are a powerful elite and do not seek advice from outside the group.

Additionally, in Groupthink, a "hidden agenda" develops among the members of elite groups. That is, all the members want a) to continue being a member because that puts them in a very privileged position, b) to please the leader in order to remain in favor, and in Chinese society subservience is deep-rooted, and c) to remain working as a group to affirm their elite status, which is greatly desired in Chinese society.

Furthermore, there is a critical "key process" in Groupthink called "consensus seeking." Consensus seeking refers to the behavior of trying to reach a unanimous agreement, which plays an important role because the group is more likely to stay together when all the members agree (rather than when they openly disagree). This is particularly fascinating because Groupthink was first discovered in western society; yet, it is a profound aspect of Chinese society. That is, whereas social harmony is the basic underlying principle and objective of Chinese society, no one will openly disagree. Therefore, the "key process" that is found in decisional fiascos is a basic and essential process in Chinese society.

The way Groupthink operates involves eight symptoms, or component behaviors: 1) The group members believe they are invulnerable; 2) they also believe they have a high morality; 3) they collectively rationalize their 
decisions; 4) they view outsiders in a stereotyped way (rather than recognizing their individual merits); 5) they put social pressure to conform on any members whose ideas seem to differ; 6) they use "self-censorship" (to avoid stating their own doubts); 7) they have the illusion that they are unanimous in their views and opinions; and 8) they voluntarily take on the role of "mind guard" to protect the group from any information that differs from their views.

It should be remembered that all thesebehaviors are a function of having a powerful leader, and wanting to remain as a member of an elite group that has close connections with the powerful leader. Therefore, the characteristics of Chinese society fit these features of Groupthink very well, such that that there are many instances in which decisions by powerful Chinese leaders were disastrous.

One example was in a university in China that had been a "teaching university," but the upper administration wanted to upgrade it to a "research university" by stressing that more research should be done. Over a period of ten years the professors gradually began to increase their research output. Then, an extremely powerful man (in a position "superior" to the university president) chose his favorite person (from another university) to be added to the university administration, giving the new administrator much power merely because of his high-level connection. In one of his decisions (which he made autonomously), he declared to everyone that there must be a minimum of 45 students in every class, which increased the student-to-teacher ratio from 17-to-1 (under the old system) to 45-to-1by his decree. Although almost everyone disagreed with this decision, no one told him. Yet, this increase had some major undesirable impacts that the new administrator did not consider. First, every professor's teaching time increased by $2.65 \%$, i.e., more than two-and-a-half times. That is, the professors had to spend more than two-and-a-half the amount of time it used to take to grade homework assignments and examinations. And they had to change their teaching method from seminars to lectures, which took more time to prepare. Thus, the more time the professors spent on teaching, the less time they had for research. In effect, by making this decision from a position of great power that no one would oppose, the new administrator single-handedly imposed a barrier to the professors in their attempts to increase their research output, and stopped the progress of the university in trying to upgrade itself to a research university.

\section{Suggested Ways to Reduce the Costs}

In the book on Groupthink, Janis [9] not only described the problems and processes that occur with it, but also suggested some ways to prevent it. Thus, the question becomes whether the suggested solutions could work in Chinese society while, at the same time, maintaining the desirable aspects of social harmony. First, here are the six methods that have been identified for preventing Groupthink from occurring, and they can all be practiced by a knowledgeable leader. Thus, to avoid Groupthink, the leader should: 1) Avoid stating their preferred position early; 2) set an example by being open to criticism; 3) invite outside experts to participate in the discussion; 4) appoint teams to (a) gather relevant data in order to generate alternative decision options, and (b) present the alternate approaches to the group; 5) appoint a "devil’s advocate," i.e., someone who is brought into the group to make open arguments that are in opposition to the possible decisions that are being discussed by the group; and 6) schedule follow-up meetings for members to state their doubts about the decision directly to the leader.

\subsection{Can Harmony Exist in Decision Making?}

Can the methods of avoiding Groupthink and its disastrous decisions work for decision-making groups in China, while also maintaining social harmony? To answer this question compare what Confucian principles advise for how a "virtuous" person, should behave. Specifically, a leader must behave according to the virtues that Confucius identified, namely, jen (humanity), li (temperance), yi (justice), and xin (courage), and zhi (wisdom) (The translations are simple to facilitate analysis) [10].

\subsection{Personal Virtues and Chinese Leaders}

Thus, to determine whether the methods of avoiding Groupthink could be practiced by Chinese leaders, it is necessary to take each method separately to analyse whether and to what extent each one is likely to be practiced.

1) Can Chinese leaders avoid stating their preferred position at the start? Yes. If they follow Confucian tradition, they will remain tacit at the outset, only stating the situation to the group, then ask for opinions, and wait 
until other opinions are expressed. This would follow the Confucian principle of temperance, which includes humility, i.e., willingness to listen to the advice of others.

2) Can Chinese leaders set a good example by being open to criticism? This also requires the virtue of temperance and humility, i.e., the ability to accept criticism.

3) Can Chinese leaders invite outside experts to participate in the discussion? To do this the Chinese leader would need the virtue of wisdom, namely, showing good judgment by broadening one's perspective through opening one's thoughts to the perspectives of other people.

4) Can Chinese leaders appoint teams to a) gather relevant data in order to generate alternative decision options, and b) present the alternate approaches to the group? This would require the virtues of justice and wisdom, namely, fairness in considering multiple opinions, and the perspicacity to acquire more knowledge about the topic that is under discussion.

5) Can Chinese leaders find and appoint a “devil's advocate," i.e., someone who is brought into the group to make open arguments that are in opposition to the possible decisions that are being discussed by the group? This could be one of the most difficult tasks for any leader, including Chinese leaders, because it requires appointing someone who will openly present arguments that are in direct opposition to the plan of action that is being discussed, which could be the leader's plan. It is difficult because it is natural to dislike someone who opposes one's ideas.

Thus, in order to take this precaution against Groupthink, the leader must have the Confucian virtues of courage (emotional strength) to listen to the criticism, temperance, in the form of humility and self-control, and justice in the form of fairness in accepting the criticism.

6) Can Chinese leaders schedule follow-up meetings for members so that they can verbally state their doubts about the decision? This may be the simplest behaviour to manage. In fact, it is common practice in Chinese society for fears and doubts to be expressed confidentially (rather than openly) in order to preserve social harmony. This involves the virtues of justice, which is in listening to such reservations, and humanity in showing consideration for the fears.

\section{Conclusions}

From the analyses made in this paper, it was observed that, despite having its origins in thousands of years of war, social harmony has become a deeply rooted guiding principle in Chinese society. It was also observed that it has certain important advantages, but could also have potential disadvantages, particularly in decision making. A profound type of problem with decision making was analyzed and assessed and found to have a high likelihood of occurrence in Chinese society. The final analysis regarding whether this problem in group decision making could be prevented by Chinese leaders revealed that leaders who possesses the personal virtues identified and advocated by Confucius could indeed avoid the common, yet serious, problems of decision making by developing the Confucian virtues of courage, humanity, justice, temperance, and wisdom in their personal lives, and practicing them in their leadership behaviors.

\section{References}

[1] Dahlsgaard, K., Peterson, C. and Seligman, M. (2005) Shared Virtue: The Convergence of Valued Human Strengths across Culture and History. Review of General Psychology, 9, 203-213. http://dx.doi.org/10.1037/1089-2680.9.3.203

[2] Guo, Z. (1995) Chinese Confucian Culture and the Medical Ethical Tradition. Journal of Medical Ethics, 21, $239-246$. http://dx.doi.org/10.1136/jme.21.4.239

[3] Hu, S. (1997) Confucianism and Western Democracy. Journal of Contemporary China, 6, 347-363. http://dx.doi.org/10.1080/10670569708724282

[4] Janis, I. (1972) Victims of Groupthink. Houghton Mifflin, NY.

[5] Li, X. (2012) China at War: An Encyclopedia. ABC-CLIO, Santa Barbara, 160-161.

[6] Maslow, A. (1943) A Theory of Human Motivation. Psychological Review, 50, 370-396. http://dx.doi.org/10.1037/h0054346

[7] Riegel, J. (2013) Confucius. In: Zalta, E. (Ed.), The Stanford Encyclopedia of Philosophy. http://plato.stanford.edu/archives/sum2013/entries/confucius/

[8] Sun, T. (1993) The Art of War (Classics of Ancient China). Ballantine Books, New York.

[9] Taormina, R.J. (2013) China’s Future Role in Developing World Social Harmony. The 3rd Conference on Psychology 
and Social Harmony, Beijing.

[10] Yang, K.S. (1995) Chinese Social Orientation: An Integrative Analysis. In: Lin, T.Y., Tseng, W.S. and Yeh, Y.K., Eds., Chinese Societies and Mental Health. Oxford University Press, Hong Kong, 19-39. 